\title{
Kanatlı İntestinal Spiroketozis
}

\author{
Yavuz Çokal ${ }^{1}$, Elçin Günaydın² \\ ${ }^{1}$ Bandırma Onyedi Eylül Üniversitesi, Bandırma Meslek Yüksekokulu, Balıkesir, Türkiye \\ ${ }^{2}$ Hitit Üniversitesi, Alaca Avni Çelik Meslek Yüksekokulu, Çorum, Türkiye
}

Geliş Tarihi / Received: 26.09.2019, Kabul Tarihi / Accepted: 09.12.2019

\begin{abstract}
Özet: Kanatlı intestinal spiroketozis (KİS), ticari yumurtacı ve broyler damıllk tavuklarda, Brachyspira cinsine ait patojenik türlerin neden olduğu bir enfeksiyondur. KİS, büyüme geriliğine, yumurta verim kaybına, yem tüketiminde artışa, yumurta kabuğunun dişkı ile kirlenmesine ve yumurta kalitesinin düşmesine neden olarak ekonomik kayıplar oluşturur. Birçok ülkede kanatlılarda Brachyspira spp. varlığı ortaya konmuştur. Ülkemizde, bilgimiz dâhilinde, KİS şüpheli ve/veya sağlıklı kanatlılardan Brachyspira spp. izolasyonu ile ilgili herhangi bir rapor yoktur. Saha gözlemlerimiz, ülkemizde özellikle ticari yumurtacı sürülerde kirli yumurta problemlerinin yoğun olduğunu göstermektedir. Bu derleme çalışması ile kirli yumurta problemlerine neden olan KİS hakkında bilgi verilmesi ve bu enfeksiyona dikkatin çekilmesi amaçlanmıştır.
\end{abstract}

Anahtar kelimeler: Brachyspira, spiroketozis, broyler damızlık, yumurtacı tavuk

\section{Avian Intestinal Spirochaetosis}

\begin{abstract}
Summary: Avian intestinal spirochetosis (AIS) is an infection caused by pathogenic species belonging to Brachyspira genus in commercial layer and broiler breeder hens. AIS creates the economic losses in consequence of the growth retardation, decrease in egg production, increase in feed consumption, faecal staining of egg shells and lower egg quality. The presence of Brachyspira spp. in poultry has been revealed in many countries. In Turkey, to the best of our knowledge, there are not any reports on the isolation of Brachyspira spp. in AIS suspicious and/or healthy avian species. Our field observations shows dirty egg problems are intense in commercial laying hens in our country. This review study aimed to give information about the AIS causing dirty egg problems and draw attention to this infection.
\end{abstract}

Key words: Brachyspira, spirochaetosis, broiler breeder, laying chicken

\section{Giriş}

Spiroketlerin kanatlılarda kolonizasyonu ile ilgili ilk veriler 20. yüzyılın başlarında rapor edilmiştir (Stephens ve Hampson 2001). Oluşturduğu enfeksiyonlar (kanatlı intestinal spiroketozis, KİS) ile ilgili ilk bulgular ise 1980'li yıllarda yapılan çalışmalarda ortaya konmuştur. Hollanda'da yapılan çalışmada, ishal semptomları gösteren yumurtacı sürülerin sekum mukoza kazıntılarından spiroketler izole edilmiş ve izolatlar deneysel olarak 10 haftalık tavuklara verildiğinde, tavuklarda sulu dışkı ve gelişme geriliği ile sekumda tiflitise neden olmuştur (Davelaar ve ark. 1986). İngiltere'de yapilan çalışmada ise büyüme geriliği, yumurta veriminde gecikme ve yumurta kabuk kalite bozukluğu olan yarka sürülerin bağırsaklarında spiroketlerin varlığ1 belirlenmiştir (Griffiths ve ark. 1987). Daha sonraki y1llarda, benzer çalışmalar Avrupa, ABD, Avustralya ve Malezya gibi ülkelerde de yapılmış, yumurta verim kaybı, kronik ishal, dışk1 ile kirli yumurta üretimi olan ve ayrıca sağlıklı sürülerde Brachyspira spp. varlığı saptanmıştır (Swayne ve ark.1992; Kizerwetter-Świda ve ark. 2005; Bano ve ark. 2008; Ivanics ve ark. 2009; Myers ve ark. 2009; Amin ve ark. 2014; Mappley ve ark. 2014). Ülkemizde, bilgimiz dâhilinde, KİS şüpheli ve/veya sağlıklı kanatlılardan Brachyspira spp. izolasyonu ile ilgili herhangi bir rapor yoktur.

\section{Etiyoloji ve Epizootiyoloji}

Daha önce Treponema ve Serpulina olarak isimlendirilmiş olan (Stanton ve ark. 1991; Ochiai ve ark. 1997) Brachyspira cinsi, Spirochetes sınıfinda yer alan Brachyspiraceae ailesi içinde klasifiye edilmektedir (Paster ve Dewhirst 2000). Brachyspira türleri gram negatif, oksijen-tolerant anaerob, kan11 agarda $\beta$-hemoliz oluşturan, hareketli, helikal kıvrımlı yapıya sahip spiral şekilli bakterilerdir. 
Günümüzde Brachyspira cinsine ait tanımlanmış 7 tür; B. hyodysenteriae, B. alvinipulli, B. intermedia, B. pilosicoli, B. aalborgi, B. innocens, B. murdochii ve genus içinde olması önerilen türler; $B$. canis, $B$. pulli, B. suanatina, B. corvi, B. ibaraki, B. rattui, $B$. muridanum ve $B$. muris bulunmaktadır (Jansson ve ark 2008a, 2008b; Backhans ve ark. 2010; Jansson ve ark 2011). Brachyspira türleri bazı memelilerin (örn; domuz, köpek, rodent, insan), evcil ve yabani kanatlıların (örn; tavuk, hindi, kaz, ördek, keklik, sülün) kalın bağırsaklarında kolonize olmaktadır (Koopman ve ark. 1993; Jansson ve ark. 2001; Shivaprasad ve Duhamel 2005; Jansson ve ark 2008b; Hidalgo ve ark 2010). Patojenik türler, domuz dizanterisi, insanlarda ve kanatlilarda intestinal spiroketozis enfeksiyonları oluşturmaktadır (Swayne ve ark. 1995; Backhans ve ark. 2011).

KİS'e tavuklarda kolonize olduğu bilinen 7 türden üçü; $B$. alvinipulli, $B$. intermedia ve $B$. pilosicoli neden olmaktadır ve son iki tür ticari yumurtacı tavuklardan daha sıklıkla izole edilmektedir (Stephens ve Hampson 1999; Bano ve ark 2008; Myers ve ark. 2009). B. pilosicoli, aynı zamanda, potansiyel zoonotik patojendir (Hampson ve ark. 2006). Belçika'da süpermarketlerde satılan yumurtac1 tavuk karkaslarından B. pilosicoli, B. intermedia ve non-patojenik türlerin izole edildiği bildirilmiştir (Verlinden ve ark 2012). Domuzlar için oldukça virulent olan "domuz dizanterisi" etkeni B. hyodysenteriae'nın tavuklar için patojenik olup olmadığ 1 ile ilgili henüz net bilgi yoktur. Bakterinin Hollanda'da ishal ve verim düşüklüğü bulguları olan ticari yumurtacı sürülerden (Feberwee ve ark. 2008), Macaristan'da KİS hikâyesi olan yumurtac1 sürülerden (Ivanics ve ark. 2009), ördek (Jansson ve ark. 2001) ve Amerikan devekuşundan (Jensen ve ark. 1996) izole edildiği bildirilmiştir. Aynı zamanda, deneysel olarak broyler civcivleri enfekte ettiği ve sekumda lezyonlar oluşturduğu rapor edilmiştir (Adachi ve ark. 1985). Bazı araştırıcılar tarafindan B. hyodysenteriae tavuklar için potansiyel patojenik tür olarak bildirilmiştir (Stephens ve ark. 2005; Medhanie 2011, Roy ve ark. 2015), ancak diğer bazı çalışmalarda ise bakteri tavuklar için patojenik türler arasında bildirilmemiştir. Tavuklar için patojenik olmadığı varsayılan türler $B$. innocens, $B$. murdochii ve $B$. pulli' dir ve her üçü de patojenik türler ile birlikte KISS olgularından izole edilebil- mektedir (Stephens ve Hampson 2001; Jansson ve Pringle 2011; Verlinden ve ark. 2012).

KİS, özellikle ticari yumurtacı tavukların bir enfeksiyonudur ve broyler damızlık tavukları da etkilemektedir (Stephens ve Hampson 2001). Broyler sürülerde enfeksiyon rapor edilmemiştir. Ancak, enfekte broyler damizlıklardan elde edilen broyler sürülerin, sağlıklı sürülerden elde edilenlere göre, düşük performans gösterdiği bildirilmiştir (Dwars ve ark. 1993; Smith ve ark. 1998). KİS üretim problemlerine neden olmaktadır. Büyüme geriliğine, yumurta verim kayıplarına, yem sindiriminde problemlere, yem tüketiminde artışa ve yumurta kalitesinin düşmesine neden olarak ekonomik kayıplar oluşturmaktadır (Davelaar ve ark. 1986; Grifiths ve ark. 1987; Swayne ve ark. 1992). İngiltere'de, ticari yumurtacı tavuklarda neden olduğu ekonomik kaybın yaklaşık 18 milyon $€$ tahmin edildiği bildirilmiştir (Mappley ve ark. 2014). Değişik ülkelerde yapılan çalışmalarda, KİS klinik bulguları gösteren kümeslerde Brachyspira spp. prevalans1 daha yüksek bulunmuştur. Hollanda'da KİS klinik bulguları gösteren yumurtacı sürülerde prevalans $\% 28$, doğu Avustralya'da yumurtacı ve broyler damızlık sürülerde $\% 70$ tespit edilirken, Hollanda'da KİS klinik bulgu göstermeyen sürülerde $\% 4$ ve doğu Avustralya'da \% 15 tespit edilmiştir (Stephens ve Hampson 1999; Kizerwetter-Świda ve ark. 2005). Diğer ülkelerde yapılan çalışmalarda ise, yumurtac1 sürülerdeki prevalans batı Avustralya'da \%35 (McLaren ve ark. 1996), Polonya'da \%50 (Kizerwetter-Świda ve ark. 2005), İtalya'da \%71 (Bano ve ark. 2008), İran'da \%16.7 (Bassami ve ark. 2012) ve doğu Avustralya'da broyler damılıklarda \%43 (McLaren ve ark. 1996) saptanmıştır.

Ticari sürülerde Brachyspira spp. varlığı ile ilgili, sürü yaşı, kümes tipi, gübre atım sistemi, rezervuar hayvanlar ile direkt ya da indirekt temas, yem ve tedavi önemli risk faktörleridir (Bano ve ark. 2008; Harms ve ark 2018). Daha önce yapılan çalışmalar Brachyspira spp. varlığının yaş ile birlikte arttığını göstermektedir. Kırk haftalıktan büyük sürülerde, 40 haftalıktan küçüklere göre prevalans daha yüksek bulunmuştur (Bano ve ark. 2008; Myers ve ark. 2009). Kafes tipli kümeslerdeki Brachyspira spp. pozitiflik oranı serbest kümeslere göre daha düşük tespit edilirken altlıklı kümeslere göre fark tespit edilmemiştir (Griffiths ve ark. 1987; Jansson ve 
ark. 2008b). Gübre çukuru olan kümeslerde, gübreleri konveyör ile taşınanlara göre, Brachyspira prevalansı daha yüksek bulunmuştur (Burch ve ark. 2006). Domuz, rodentler, yabani kuşlar, su kuşları Brachyspira spp., özellikle B. pilosicoli taşı1cısıdir (Griffiths ve ark. 1987; Backhans ve ark. 2010, 2011). Tavuk sürülerine yabani kuşlar, kemirgenler, böcekler, kedi, köpek ve çiftlik hayvanları (domuz, at) ile diğer kümes hayvanları (ördek, kaz, hindi, sülün) ve insanlar aracılığıyla bulaşma söz konusu olabilmektedir (Stephens ve Hampson 2002; Hampson ve ark. 2006; Hampson 2018). Bulaşmada arac1 çevre ile daha fazla temas halinde olması nedeniyle Brachyspira enfeksiyonları özellikle serbest yetiştiricilik yapan tavuk çiftliklerinde daha fazla yaygındir (Wagenaar ve ark. 2003).

\section{Patogenezis}

Bağırsak spiroketozisin patogenezisi tam olarak anlaşılamamıştır. Bu konudaki çalışmalar daha çok geniş konakçı spektrumuna sahip $B$. pilosicoli üzerinde yoğunlaşmıştır ve şimdiye kadar enfeksiyon sürecine katkıda bulunan birkaç virulens faktörü tanımlanmıştır (Roy ve ark. 2015). Enfeksiyon fekal-oral yolla gerçekleşmektedir. Su kuşlarında kontamine sulardan kloakadan retroperistaltik olarak sekal enfeksiyonun gerçekleşebileceği ileri sürülmüștür (Hampson 2018). Ağız yoluyla alınan etken kalın bağırsak lumenine ulaşır. Mide ve ince bağırsakları geçişte mide içeriği ve organik maddelerce korunmaktadır. B. pilosicoli flagellaları sayesinde aktif hareketlidir. Bağırsak mukozasında fiziksel bariyer oluşturan mukusa karşı kemotaksisi kodlayan birçok gene sahiptir. Bu sayede mukusa kemoatraksiyon gösterir ve kolonizasyonda önemli avantaj sağlar. Bakteri sialidaz enzimlerine benzer spesifik enzimler sentezler. Bu enzimler sayesinde mukusu hidrolize ederek kolon mukozası boyunca penetre olur ve hücrenin lumen yüzeyine bağlanır. Farklı suşların hem motilitelerinde hem de mukusa yönelik kemotaktik yanıtlarında farklılıklar gösterebileceği, bu durumun kolonizasyon potansiyellerini etkileyebileceği bildirilmiştir (Roy ve ark. 2015). Bakteri yüzey lipoproteinleri hücre yüzeyindeki spesifik reseptörler ile etkileşerek bağlanmayı kolaylaştırırlar. Yaygın bir kolonizasyon meydana geldiğinde, kolonik enterositler boyunca su ve elektro- lit emilimine fiziksel bir bariyer direnci oluşur ve bu da ishale neden olur (Mappley ve ark. 2014).

\section{Klinik Belirtiler}

Enfekte sürülerde, kronik ishal, özellikle yapışkan veya hafif köpüklü, karamel renkli dıșkı, vent bölgesinin kirli-bulaşık olması (pasty vent sendrom), yumurta kabuğunun dıșkı ile kirlenmesi ve tavuklarda halsizlik-durgunluk genel bulgulardır. Ayrıca, yumurtlamaya başlamada gecikme, büyüme geriliği, yumurta ağırlığında ve karetenoid içeriğinde azalma da görülebilmektedir (McLaren ve ark. 1997; Stephens ve Hampson 2001; Jansson ve ark. 2001). Hastalıkta, kümesteki hayvanların \%5-25'inde (kronik) ishal şekillenebilmektedir (Swayne ve ark. 1992; Stephens ve Hampson 1999; KizerwetterŚwida ve ark. 2005). Dışkıda renk ve kıvam değişiklikleri meydana gelir ve gaz üretimindeki artıştan dolayı köpüklü bir hal alabilir (cappuccino faeces). İleri durumlarda dışkıda mukus ve kan görülebilir (Roy ve ark. 2015). İshalden dolayı dıșkı daha sulu hale geldiğinden yumurta kabuğunun dışkı ile kirlenmesi daha da artmaktadır. Bu nedenle kirli yumurta üretimi olan sürülerde Brachyspira spp. prevalansı daha yüksek bulunmaktadır (McLaren ve ark. 1996, Stephens ve Hampson 1999, Bano ve ark. 2008). Ontario/Kanada'da yumurtacı sürülerde yapılan bir çalışmada, kirli yumurta problemi olan sürülerin $\% 63,5$ 'i, temiz sürülerin $\% 24,3$ 'ü Brachyspira spp. pozitif bulunmuş ve kirli yumurta problemi ile Brachyspira spp. varlığı arasında güçlü bir ilişkinin olduğu rapor edilmiştir (Medhanie ve ark. 2013). Medhanie (2011) Brachyspira spp. prevalansının temiz yumurta üreten sürülerde kirli yumurta üretenlere göre \%19-56 oranlarında daha düşük olduğunun tahmin edildiğini bildirmiştir.

\section{Teşhis}

KİS klinik bulgularının hafif, değişken ve nonspesifik olması nedeniyle ticari kanatlı sürülerde enfeksiyonun varlığı genellikle fark edilmemekte ve gözden kaçabilmektedir. Sürüde enfeksiyona bağl olarak șekillenen ishal ve yumurta verim düşüklügü belirgin bulgular olsa da patognomik değildir. Mikroskobik muayene ile spiroketlerin varlığı, karakteristik morfolojileri ve hareketleri 1șık, faz-kontrast ya da karanlık alan mikroskoplarıyla izlenebilir 
(Mappley ve ark. 2014). Teşhiste altın standart olarak kabul görmüş bir yöntem yoktur (Harms ve ark. 2018). Yapılan çalışmalarda çoğunlukla kültürel metot ve moleküler yöntemler birlikte kullanılmıştır (Stephens ve Hampson 1999; Kizerwetter-Świda ve ark. 2005; Feberwee ve ark. 2008; Jansson ve ark. 2008a). Doğası gereği nazlı ve yavaş üreyen Brachyspira türleri kan ve/veya serum ilave edilmiş katı veya sıvı ortamlarda üreyebilir. İzolasyon için taze dışk1 ve kloakal svap örneklerinden selektif katı besiyerlerine ekimler yapılır ve anaerobik olarak inkube edilir. Selektif besiyerlerine spektinomisin, rifampisin, polimiksin, kolistin ve vankomisin gibi farklı antibiyotik kombinasyonları ilave edilmektedir (Kunkle ve ark. 1986, 1988; Fellstrom ve ark. 1995). Son dönemde yapılan çalışmalarda, selektif katı besiyeri olarak çoğunlukla farklı antibiyotikler ve defibrine sığır ya da koyun kanı ilave edilmiş Triptikaz Soy Agar kullanılmıştır (Davelaar ve ark. 1986; Phillips ve ark. 2003; Feberwee ve ark. 2008). Pleytler $37^{\circ} \mathrm{C}-42^{\circ} \mathrm{C}$ ' de $2-5$ gün inkübe edilmektedir. $42^{\circ} \mathrm{C}^{\prime}$ de inkubasyonun diğer non-spiroketal bakterilerin üremesini inhibe ettiği için daha avantajlı gözüktüğü bildirilmiştir (Stephens ve Hampson 2001; Phillips 2006). Primer pleytten sonra saf kültür elde edilinceye kadar subkültür uygulamasına devam edilmektedir. Brachyspira türleri katı besiyerlerinde göze çarpan ayrı koloniler oluşturmazlar, bunun yerine agar yüzeyine yayılmış sis benzeri ince bir film tabakası gibi birleşik bir üreme gösterirler. Kanlı agarda $\beta$-hemoliz oluştururlar ve hemoliz oluşumu üreme gözlenmeden önce şekillenebilir (Phillips 2006). İdentifikasyonda, izolatların mikroskobik morfolojileri ile hemoliz, indol, hippurat, $\alpha$-galaktosidaz, $\alpha$-glukosidaz ve $\beta$-glukosidaz enzim aktiviteleri belirlenmektedir. Enzim aktivitelerini belirlemede daha çok ticari kitler kullanılmaktadır (Kizerwetter-Świda ve ark. 2005; Feberwee ve ark. 2008). Kanatlılarda kolonize olabilen türler arasında $B$. hyodysenteriae güçlü $\beta$-hemolitiktir, diğerleri zayıf $\beta$-hemolitik özelliktedir. B. hyodysenteriae indol pozitiftir, ancak bazı izolatların indol negatif oldu$\breve{g u}$ (Hommez ve ark. 1998) ve bazı non- B. hyodysenteriae spiroketlerin de güçlü $\beta$-hemolitik olduğu (Neef ve ark. 1994) gösterilmiştir. Yine, ördeklerde $B$. hyodysenteriae yanısıra diğer güçlü $\beta$-hemolitik ve indol pozitif spiroketlerin varlığ bildirilmiştir (Jansson ve ark. 2004). B. pilosicoli zayıf $\beta$-hemolitiktir ve genel olarak hippurat pozitif, indol negatif- tir. Domuzlardan hippurat negatif B. pilosicoli izole edilmiştir, bu nedenle identifikasyonda hippurat pozitif ve negatif olarak dikkate alınması gerektiği önerilmiştir (Thomson ve ark. 2001). Bazı B. pilosicoli insan izolatları indol pozitif bulunmuştur. $B$. intermedia zayıf $\beta$-hemolitik, indol pozitiftir ve "intermedia" ismi biyokimyasal olarak $B$. hyodysenteriae ve $B$. innocens arasinda bir pozisyonda olmasindan gelmektedir (Stanton ve ark. 1997). Türler arasında olan fenotipik farklılıklardaki bu tür uyumsuzluklar rutin identifikasyon çalışmalarını zorlaştırmaktadir (Stephens ve ark. 2005). Bu nedenle de identifikasyonda moleküler tekniklerin kullanılmas1 önem arz etmektedir. Günümüzdeki çoğu çalışmada, Brachyspira türlerinin cins ve tür düzeyinde moleküler identifikasyonunda 16S rRNA, 23S rRNA, NADH oxidase (nox) hedef genlerine dönük dizayn edilmiş Polimeraz Zincir Reaksiyonları kullanılmıştır (Atyeo ve ark. 1999; Suriyaarachchi ve ark. 2000; Jansson ve ark. 2004; Kizerwetter-Świda ve ark. 2005; Phillips 2006; Feberwee ve ark. 2008; Verlinden ve ark. 2012). Son dönemde, Brachyspira spp. identifikasyonda daha hızlı ve ucuz bir yöntem olan ve bakteri protein profillerinin (çevresel koşullardan daha az etkilenen ribozomal proteinlerin) çıkarılması esasına dayanan Matrix-assisted laser desorption ionization time-of-flight mass spectrometry (MALDI-TOF MS) kullanımı bildirilmiştir (Calderaro ve ark. 2013).

\section{Tedavi ve Korunma}

Günümüzde KİS enfeksiyonlarına karşı sık1 biyogüvenlik önlemlerinin alınması ve tedavide antibiyotiklerin kullanılması temel uygulamalardır (Mappley ve ark. 2014; Roy ve ark. 2015). Temizlik ve dezenfeksiyon uygulamaları, etkili rodent, böcek ve yabani kuşların kontrolü, personel girişi ve su kaynaklarının kontrolü gibi önlemlerin alınması önemlidir. Kuaterner amonyum bileşikleri, iodin, klorin ve hidrojen peroksit Brachyspira türlerini inaktive eder (Phillips ve ark. 2003). Tedavi amaçlı broyler damızlık ve yumurtacı sürülerde pleuromutilin, makrolid ve linkozamid grubu antibiyotiklerin kullanıldığı ve olumlu etkilerin sağlandığına dair deneme ve saha çalışmaları vardır (Stephens ve Hampson 2002; Burch ve ark 2006; Roy 2016). En yaygın kullanılanı, ribozomun $50 \mathrm{~S}$ bölgesine bağlanarak protein sentezini inhibe eden bakteriostatik 
etkili, pleuromutilin ailesinin bir üyesi olan tiamulindir. Burch ve ark. (2006) B. pilosicoli kaynaklı KİS enfekte yumurtacı sürülerde yaptığı saha çalışmasında, 5 gün boyunca içme suyuna $12.5 \mathrm{mg} / \mathrm{kg}$ dozda tiamulin uygulamasının sürülerde, yumurta üretimi ve yumurta ağırlığ 1 veriminde artış, mortalite de azalma gibi olumlu etkiler yaptığını bildirmiştir. Antibiyotik tedavisinin, özellikle ticari yumurtacı sürülerde, direnç ve yumurtada kalıntı sorunlarına neden olacağına dair kaygılar devam etmektedir. $\mathrm{Bu}$ nedenle alternatif tedavi/korunma stratejileri araştırılmıştır. Rekabetçi dışlama mekanizması ile etki gösteren probiyotikler ile ilgili yapılan çalışmalarda olumlu sonuçlar alınmıştır (Mappley ve ark. 2011; Mappley ve ark. 2013). Avrupa Gıda Güvenliği Otoritesi (EFSA) tarafından çiftlik hayvanların beslenmesinde kullanımı güvenilir olarak kabul edilen Lactobacillus salivarius ve Lactobacillus reuteri ile yapılan bir çalışmada, her iki laktobasilin B. pilosicoli'nin hareketini, üremesini ve hücreye bağlanmasını antagonize ettiği görülmüştür. (Mappley ve ark. 2011). Kullanılan ticari bir aşı yoktur. B. intermedia HB60 suşundan hazırlanan otojen bakterin aşısı deneysel enfekte edilmiş ticari yumurtacı tavuklarda hastalığg önlememiştir (Amin ve ark. 2009).

\section{Sonuç}

Birçok ülkede tavuklarda KİS varlığı ve oluşturduğu ekonomik kayıplar yapılan çalışmalarla ortaya konmuştur. 2006 yılında Avrupa Birliğine üye ülkelerde profilaktif amaçlı antibiyotik kullanımının yasaklanmasının ardından KIS vakalarında artış gözlendiği bildirilmiştir (Mappley ve ark. 2011, Roy ve ark. 2015). Ülkemizde ise bu konuda, bilgimiz dâhilinde, herhangi bir çalışma yoktur. Dolayısıyla KİS enfeksiyonunun ülkemizdeki durumu bilinmemektedir. Saha gözlemlerimiz ise özellikle ticari yumurtac1 sürülerde kronik ishal ve kirli yumurta problemlerinin yoğun olduğunu göstermektedir. Ülkemizde bu konuda çalışmalara ihtiyaç vardır.

\section{Kaynaklar}

1. Adachi Y, Sveyoshi M, Miyagawa E, Minato H, Shoya S. (1985). Experimental infection of young broiler chick with Treponema hyodysenteriae. Microbiol Immunol. 29, 683688. DOI: 10.1111/j.1348-0421.1985.tb00872.x

2. Amin MM, Phillips ND, La T, Hampson DJ. (2009). Vaccination with an autogenous bacterin fails to prevent colonization by Brachyspira intermedia in experimentally infected laying chickens. Vet Microbiol. 133, 372-376. DOI: 10.1016/j.vetmic.2008.07.007

3. Amin MM, Phillips ND, La T, Robertson ID, Hampson DJ. (2014). Intestinal spirochaetes (Brachyspira spp.) colonizing flocks of layer and breeder chickens in Malaysia. Avian Pathology. 43:6, 501-505. DOI: 10.1080/03079457.2014.966056

4. Atyeo RF, Stanton TB, Jensen NS, Suriyaarachichi DS, Hampson DJ. (1999). Differentiation of Serpulina species by NADH oxidase gene (nox) sequence comparisons and nox-based polymerase chain reaction tests. Vet Microbiol. 67, 47-60. DOI: 10.1016/S0378-1135(99)00030-9

5. Backhans A, Johansson KE, Fellström C. (2010). Phenotypic and molecular characterization of Brachyspira spp. isolated from wild rodents. Env Microbiol Rep. 2(6), 720-772. DOI:10.1111/j.1758-2229.2010.00165.x

6. Backhans A, Jansson DS, Aspa'n A, Fellström C. (2011). Typing of Brachyspira spp. from rodents, pigs and chickens on Swedish farms. Vet Microbiol. 153, 156-162. DOI:10.1016/j.vetmic.2011.03.023

7. Bano L, Merialdi G, Bonilauri P, Dall'Anese G, Capello K, Comin D, Cattoli G, Sanguinetti V, Hampson DJ, Agnoletti F. (2008). Prevalence, disease associations and risk factors for colonization with intestinal spirochaetes (Brachyspira spp.) in flocks of laying hens in north-eastern Italy. Avian Pathol. 37(3), 81-86. DOI:10.1080/03079450802043726

8. Bassami M-R, Jamshidi A, Kasaei A, Mohamadi A. (2012). Isolation and Identification of Brachyspira pilosicoli from laying hens flocks, using conventional culture and molecular methods in Mashhad, Iran. Iranian Journal of Veterinary Science and Technology. 4, 29-36.

9. Burch DGS, Harding C, Alvarez R, Valks M. (2006). Treatment of a field case of avian intestinal spirochaetosis caused by Brachyspira pilosicoli with tiamulin. Avian Pathol. 35, 211-216. DOI:10.1080/03079450600711011

10. Calderaro A, Piccola G, Montecchini S, Buttrini M, Gorrini C, Rossi S, Arcangeletti MC, Conto FD, Medici MC, Chezzi C. (2013). MALDI-TOF MS analysis of human and animal Brachyspira species and benefits of database extension. Journal of Proteomics. 78, 273-280. DOI:10.1016/j. jprot.2012.09.027

11. Davelaar FG, Smith HF, Hovind-Hougen K, Dwars RM, Vandervalk PC. (1986). Infectious typhlitis in chickens caused by spirochetes. Avian Pathol. 15, 247-258. DOI:10.1080/03079458608436285

12. Dwars RM, Davelaar FG, Smit HF. (1993). Infection of broiler parent hens with avian intestinal spirochaetes: Effects on egg production and chick quality. Avian Pathol. 22, 693-701. DOI:10.1080/03079459308418957

13. Feberwee A, Hampson DJ, Phillips ND, La T, van der Heijden HMJF, Wellenberg GJ, Dwars RM, Landman WJM. (2008). Identification of Brachyspira hyodysenteriae and other pathogenic Brachyspira species in chickens from laying flocks with diarrhea or reduced production or both. J Clin Microbiol. 46 (2), 593-600. DOI: 10.1128/ JCM.01829-07 
14. Fellstrom C, Petterson B, Uhlen M, Gunnarsson A, Johansson KE. (1995). Phylogeny of Serpulina based on sequence analyses of the 16S rRNA gene and comparison with a scheme involving biochemical classification. Res Vet Sci. 59, 5-9. DOI: 10.1016/0034-5288(95)90022-5

15. Griffiths IB, Hunt BW, Lister SA, Lamont MH. (1987). Retarted growth rate and delayed onset of egg production associated with spirochaete infection in pullets. Vet Rec. $121,35-37$

16. Hampson DJ, Oxberry SL, La T. (2006). Potential for zoonotic transmission of Brachyspira pilosicoli. Emerg Infect Dis. 12 (5), 869-870. DOI: 10.3201/eid1205.051180

17. Hampson DJ. (2018). The spirochete Brachyspira pilosico$l i$, enteric pathogen of animals and humans. Clin Microbiol Rev 31: e00087-17. DOI: 10.1128/CMR .00087-17.

18. Harms M, Schmidt V, Heydel T, Hauptmann J, Ahlers C, Bergmann R, Baums CG. (2018). Differentiation of Brachyspira spp. isolated from laying hens using PCRbased methods and matrix-assisted laser desorption/ ionization time-of-flight mass spectrometry. $J$ Vet Diagn Invest. 30(4), 545-553. DOI: 10.1177/1040638718772319

19. Hidalgo A, Rubio P, Osorio J, Carvajal A. (2010). Prevalence of Brachyspira pilosicoli and "Brachyspira canis" in dogs and their association with diarrhoea. Vet Microbiol. 146, 356-360. DOI:10.1016/j.vetmic.2010.05.016

20. Hommez J, Castryck F, Haesebrouck F, Devriese LA. (1998). Identification of porcine Serpulina strains in routine diagnostic bacteriology. Vet Microbiol. 62 (2), 163-169. DOI: 10.1016/S0378-1135(98)00204-1

21. Ivanics E, Glavists R, Thuma A, Simon A, Berta P, Kaszanyitzky E, Samu P, Dencsö L, Ursu K, Dản A. (2009). Intestinal spirochaetosis (Brachyspirosis) in Hungarian laying hen flocks. Magy Allatorvosok. 131, 323-330.

22. Jansson DS, Bröjer C, Gavier-Widén D, Gunnarsson A, Fellström C. (2001). Brachyspira spp. (Serpulina spp.) in birds: a review and results from a study Swedish game birds. Anim Health Res Rev. 2(1), 93-100. DOI: 10.1079/ AHRR200122

23. Jansson DS., Johansson KE., Olofsson T, Rasback T, Vagsholm I, Pettersson B, Gunnarsson A, Fellström C. (2004). Brachyspira hyodysenteriae and other strong betahaemolytic and indole-positive spirochaetes isolated from mallards (Anas platyrhynchos). J Med Microbiol. 53, 293300. DOI:10.1099/jmm.0.05488-0

24. Jansson DS, Fellström C, Johansson KE. (2008a). Intestinal spirochetes isolated from wild-living jackdaws, hooded crows and rooks (genus Corvus): Provisionally designated "Brachyspira corvi"sp. nov. Anaerobe. 14, 287-295. DOI: 10.1016/j.anaerobe.2008.09.002

25. Jansson DS, Fellström C, Råsbäck T, Vågsholm I, Gunnarsson , Ingermaa F, Johansson KE. (2008b). Phenotypic and molecular characterization of Brachyspira spp. isolated from laying hens in different housing systems. Vet Microbiol. 130, 348-362. DOI:10.1016/j.vetmic.2008.02.010

26. Jansson DS, Persson M, Zimmerman U, Johansson KE. (2011). Phenotypic and genetic diversity among intestinal spirochaetes (genus Brachyspira) in free-living wild mallards (Anas platyrhynchos) sampled in southern Sweden. Syst Appl Microbiol. 34, 566-575. DOI: 10.1016/j.syapm.2011.10.001

27. Jansson DS, Pringle M. (2011). Antimicrobial susceptibility of Brachyspira spp. isolated from commercial laying hens and free-living wild mallards (Anas platyrhynchos). Avian Pathol. 40(4), 387-393. DOI:10.1080/03079457.2011.588 197

28. Jensen NS, Stanton TB, Swayne DE. (1996). Identification of the swine pathogen Serpulina hyodysenteriae in rheas (Rhea americana). Vet Microbiol. 52, 259-269. DOI: 10.1016/S0378-1135(96)00076-4

29. Kizerwetter-Świda M, Rzewuska M, Binek M. (2005). Characterization of Brachyspira sp. strains isolated from flock of hens with diarrhoea. Bull Vet Inst Pulawy. 49, 169173.

30. Koopman MBH, Käsbohrer A, Beckmann G, van der Zeijst BAM, Kustera JG. (1993). Genetic Similarity of Intestinal Spirochetes from Humans and Various Animal Species. $J$ Clin Microbiol. 31 (3), 711-716.

31. Kunkle RA, Harris DL, Kinyon JM. (1986). Autoclaved liquid medium for propagation of Treponema hyodysenteriae. J Clin Microbiol. 24, 669-671.

32. Kunkle RA., Kinyon JM. (1988). Improved selective medium for the isolation of Treponema hyodysenteriae. J Clin Microbiol. 26, 2357-2360.

33. Mappley LJ, Tchórzewska MA, Cooley WA, Woodward MJ, La Ragione RM. (2011). Lactobacilli antagonize the growth, motility, and adherence of Brachyspira pilosicoli: a potential intervention against avian intestinal spirochetosis. Appl Environ Microbiol. 77, 5402-5411. DOI: 10.1128/ AEM.00185-11

34. Mappley LJ, Tchórzewska MA, Nunez A, Woodward MJ, Bramley PM, La Ragione RM. (2013). Oral treatment of chickens with Lactobacillus reuteri LM1 reduces Brachyspira pilosicoli-induced pathology. J Med Microbiol. 62, 287-296. DOI:10.1099/jmm.0.051862-0

35. Mappley LJ, La Ragione RM, Woodward MJ. (2014). Brachyspira and its role in avian intestinal spirochaetosis. Vet Microbiol. 168, 245-260. DOI: 10.1016/j.vetmic.2013.11.019

36. McLaren AJ, Hompson DJ, Wylie SL. (1996). The prevalance of intestinal spirochetes in poultry in Western Australia. Aust Vet J. 74, 319-321. DOI: 10.1111/j.17510813.1996.tb13792.x

37. McLaren AJ, Trott DJ, Swayne DE, Oxberry SL, Hompson DJ. (1997). Genetic and phenotypic characterization of intestinal spirochetes colonizing chickens and allocation of known pathogenic isolates to three distinct genetic groups. J Clin Microbiol. 35, 412-417.

38. Medhanie GA. (2011). The epidemiology of Brachyspira species in Ontario layer chicken flocks. Master of Science, The University of Guelph, Guelph, Ontario, Canada.

39. Medhanie GA, McEwen SA, Weber, Sanei B, Cooley L, Houghton S, Slavic D, Guerin MT. (2013). Risk factors associated with the colonization of Ontario layer chicken 
flocks with Brachyspira species. Prev Vet Med. 109, 304311. DOI: 10.1016/j.prevetmed.2012.09.017.

40. Myers SE, Dunn PA, Philips ND, La T, Hampson DJ. (2009). Brachyspira intermedia and Brachyspira pilosicoli are commonly found in older laying flocks in Pennsylvania. Avian Dis. 53, 533-537. DOI: 10.1637/8900-042709Reg.1

41. Neef NA, Lysons RJ, Trott DJ, Hompson DJ, Jones PW, Morgan JH. (1994). Pathogenicity of porcine intestinal spirochetes in gnotobiotic pigs. Infect Immun. 62, 2395-2403.

42. Ochiai S, Adachi Y, Mori K. (1997). Unification of the genera Serpulina and Brachyspira, and proposals of Brachyspira hyodysenteriae comb. nov., Brachyspira innocens comb. nov. and Brachyspira pilosicoli comb. nov. Microbiol Immunol. 41, 445-452. DOI: 10.1111/j.13480421.1997.tb01877.x

43. Paster BJ, Dewhirst FE. (2000). Phylogenetic Foundation of Spirochetes. J Mol Microbiol Biotechnol. 2 (4), 341-344.

44. Phillips ND, La T, Hampson DJ. (2003) Survival of intestinal spirochaete strains from chickens in the presence of disinfectants and in faeces held at different temperatures. Avian Pathol. 32(6), 639-643. DOI: $10.1080 / 03079450310001610677$

45. Phillips ND. (2006). Diagnosis, molecular epidemiology and control of avian intestinal spirochaetosis, Doctor of Philosophy, Murdoch University, Western Australia.

46. Roy CIL, Mappley LJ, Ragione RML, Woodward MJ, Claus SP. (2015). Brachyspira pilosicoli-induced avian intestinal spirochaetosis. Microb Ecol Health D. 26:1, 28853 DOI: $10.3402 /$ mehd.v26.28853

47. Roy CL. (2016). Impact of tiamulin against Brachyspira pilosicoli induced avian intestinal spirochaetosis. Doktora Tezi, School of Food, Chemistry and Pharmacy, The University of Reading.

48. Shivaprasad HL, Duhamel GE. (2005). Cecal spirochetosis caused by Brachyspira pilosicoli in commercial turkeys. Avian Dis. 49 (4), 609-613. DOI: 10.1637/7383-052005.1

49. Smith HF, Dwars RM, Davelaar FG, Wijtten GAW. (1998). Observations on the influence of intestinal spirochaetosis in broiler breeders on the performance of their progeny and on egg production. Avian Pathol. 27, 133-141. DOI: $10.1080 / 03079459808419314$

50. Stanton TB, Jensen NS, Casey TA, Tardoff LA, Dewhirst FE, Paster BJ. (1991). Reclasification of Treponema hyodysenteriae and Treponema innocens in a new genus, Serpula gen. nov., as Serpula hyodysenteriae comb. nov. and Serpula innens comb. nov. Int J Syst Bacteriol. 41, 5058 .
51. Stanton TB, Fournie-Amazouz E, Postic D, Trott DJ, Grimont PAD, Baranton G, Hampson DJ, Saint Girons I. (1997). Recognition of two new species of intestinal spirochetes: Serpulina intermedia sp. nov. and Serpulina murdochii sp. nov. Int J Syst Bacteriol. 47, 1007-1012.

52. Stephens CP, Hampson DJ. (1999). Prevalence and disease association of intestinal spirochaetes in chickens in Eastern Australia. Avian Pathol. 28, 447-454. DOI: 10.1080/03079459994461

53. Stephens CP, Hampson DJ. (2001). Intestinal spirochete infections of chickens: a review of disease associations, epidemiology and control. Anim Health Res Rev, 2(1), 83-91. DOI: 10.1079/AHRR200116

54. Stephens CP, Hampson DJ. (2002). Evaluation of tiamulin and lincomycin for the treatment of broiler breeders experimentally infected with the intestinal spirochaete Brachyspira pilosicoli. Avian Pathol. 31, 299-304. DOI:10.1080/03079450220136501

55. Stephens CP, Oxberry SL, Nyree D, Phillips ND, La T, Hampson DJ. (2005). The use of multilocus enzyme electrophoresis to characterise intestinal spirochaetes (Brachyspira spp.) colonising hens in commercial flocks. Vet Microbiol. 107, 149-157. DOI:10.1016/j.vetmic.2005.01.011

56. Suriyaarachchi DS, Mikosza ASJ, Atyeo RF, Hampson DJ. (2000). Evaluation of a $23 \mathrm{~S}$ rDNA polymerase chain reaction assay for identification of Serpulina intermedia, and strain typing using pulsed-field gel electrophoresis. Vet Microbiol. 71, 139-148. DOI: 10.1016/S03781135(99)00153-4

57. Swayne DE, Bermudez AJ, Sagartz JE, Eaton KA, Manfort JD, Stoutenburg JW, Hayes JR. (1992). Association of cecal spirochetes with pasty wents and dirty eggshells in layer. Avian Dis. 36, 776-781. DOI: 10.2307/1591784

58. Swayne DE, Eaton KA, Stoutenburg J, Trott DJ, Hampson DJ, Jensen NS. (1995). Identification of a New Intestinal Spirochete with Pathogenicity for Chickens. Infect Immun. 63, 430-436.

59. Thomson JR, Smith WJ, Murray BP, Murray D, Dick JE, Sumption KJ. (2001). Porcine enteric spirochete infections in UK: surveillance data and preliminary investigation of atypical isolates. Anim Health Res Rev. 2, 31-36.

60. Verlinden M, Pasmans F, Garmyn A, De Zutter L, Haesebrouck F, Martel A. (2012). Occurrence of viable Brachyspira spp. on carcasses of spent laying hens from supermarkets. Food Microbiol. 32, 321-324.

61. Wagenaar J, Van Bergen M, van der Graaf L. Landman W. (2003). Free-range chickens show a higher incidence of Brachyspira infections in the Netherlands. In Proceedings of the Second International Conference on Colonic Spirochaetal Infections in Animals and Humans, April 2-4, Eddleston, Scotland, UK. 